\title{
Review Article \\ Clinical Relevance of the Advanced Microbiologic and Biochemical Investigations in Periodontal Diagnosis: A Critical Analysis
}

\author{
Vishakha Grover, ${ }^{1}$ Anoop Kapoor, ${ }^{2}$ Ranjan Malhotra, ${ }^{1}$ and Gagandeep Kaur ${ }^{1}$ \\ ${ }^{1}$ Department of Periodontics \& Oral Implantology, National Dental College \& Hospital, Gulabgarh, Derabassi, District SAS Nagar, \\ Mohali, Punjab 140507, India \\ ${ }^{2}$ Department of Periodontics \& Oral Implantology, M.N.D.A.V. Dental College \& Hospital, Solan, Himachal Pradesh 173223, India
}

Correspondence should be addressed to Vishakha Grover; vishakha_grover@rediffmail.com

Received 5 May 2014; Accepted 16 October 2014; Published 17 November 2014

Academic Editor: Gul Atilla

Copyright (C) 2014 Vishakha Grover et al. This is an open access article distributed under the Creative Commons Attribution License, which permits unrestricted use, distribution, and reproduction in any medium, provided the original work is properly cited.

New approaches to periodontal diagnosis, including advanced microbiologic, biochemical, and genetic tests, have been shown to provide the clinician with the information not available by traditional means. The purpose of a diagnostic test is to confirm, exclude, classify, or monitor disease to guide treatment. Their clinical value depends on whether the information they provide leads to improved patient outcomes. This can be assessed by randomized trials, which compare patient outcomes from the new diagnostic test versus the old test strategy. Being nonmandatory for marketing approval, such trials are not always feasible because of large sample sizes requirements. So, many diagnostic tests enter the practice without being critically analysed for any additional benefits. Effective diagnosis is just as essential as the selection of effective treatments for the success of periodontal therapy. So, the current paper aims to focus on the practical utility of this rapidly emerging plethora of periodontal diagnostic tools, emphasizing the critical issues surrounding the clinical application of microbiologic and biochemical investigations, employed for periodontal diagnosis.

\section{Introduction}

"Periodontal diagnosis" is an important tag that a clinician ties on the periodontal disease condition of the patient, capturing all his past experience with the condition in question. The entire constellation of signs and symptoms, along with a detailed history, is elicited, documented, and interpreted to reach at a diagnosis. Most often an accurate diagnosis is the very first concrete step towards the planning and execution of an appropriate individualized treatment plan, contributing significantly towards the success of the therapy [1].

Clinical diagnostic parameters that were introduced more than half a century ago continue to function as the basic model for periodontal diagnosis in current clinical practice as well. A periodontal diagnostic tool, in general, provides pertinent information for differential diagnosis, localization of disease, and severity of infection. They include various disease characteristics such as probing pocket depths, bleeding on probing, clinical attachment levels, plaque index, and radiographs quantifying alveolar bone levels [2, 3]. Although there have been significant advances in the understanding of the etiopathogenesis of periodontal disease over the past 45 decades, the traditional methods by which clinicians diagnose periodontal disease have remained virtually unchanged [4].

These diagnostics were called in to question during the early 1980s, when longitudinal clinical studies demonstrated that long-held concepts concerning the natural history of periodontal disease required modification [5]. More recent paradigms for periodontitis diagnosis include the possibility of several disease types, based primarily on the rate of disease progression, the distribution of the disease within the mouth, and the chronological age of the patient as well as active and inactive stages of the disease. Since then, clinicians got to be interested in assessment tools that should give them information in the following three areas: 
(i) diagnostic tests that could determine whether the periodontal disease process is currently active (progressive loss of attachment) with accuracy above what can be determined by traditional clinical indicators;

(ii) risk assessment, by which clinicians could identify patients or specific sites that are at higher risk for disease onset;

(iii) prognosis assessment, by which clinicians could predict the course of disease with or without treatment $[6,7]$.

Traditional clinical assessments do not enable a practitioner performing a single routine periodontal examination to determine whether active tissue destruction is occurring, for example, no definitive method to determine that gingival inflammation in a successfully treated case of periodontitis represents early recurrent disease or gingivitis on a stable but reduced periodontium $[4,8]$. Albeit easy to use, costeffective, and relatively noninvasive, clinical attachment loss evaluation using the periodontal probe measures damage from past episodes of destruction but requires a $2-3 \mathrm{~mm}$ threshold change before a site with significant breakdown can be identified. Demonstrating progressive loss of periodontal support requires longitudinal assessment. Current diagnostic methodologies do not enable us to accurately predict which periodontal sites, teeth, or individuals are susceptible to further periodontal breakdown $[2,9,10]$. Given the limitations of current diagnostic tools, researchers are continuously working to develop techniques that focus on the early detection, disease activity, and host susceptibility of disease $[4,8]$.

With the advent of so many new diagnostic tests developed in past few decades, we must not mislead ourselves to the belief that everything we can measure will always be helpful. Many traditionally taught methods have never been scrutinized for their precise benefits, and new tests are made available without any properly documented utility. To determine the diagnostic utility (the quality of being of practical use), detailed information is needed on how a test or diagnostic algorithm performs in a specific setting and what the consequences of a positive or negative test might be [8]. Detection of periodontal disease is seldom the principal problem in periodontics. One and the same test can have variable utility depending on the information already available before the test is done. The ideal diagnostic test should be $[10,11]$

(i) highly specific,

(ii) highly sensitive,

(iii) reproducible,

(iv) quantitative,

(v) simple to perform,

(vi) rapid,

(vii) a one-stage or a two-stage procedure,

(viii) noninvasive,

(ix) versatile in terms of sample handling, storage, and transport, (x) amenable to chairside use,

(xi) economical,

(xii) dependent upon simple and robust instrumentation.

The clinical value further largely depends on finding truly new information, any treatment alternative, cost effectiveness, and safety profile of the newly developed test protocol. Additional information (for, e.g., the cost of test, time taken, and patient acceptance) also should be sorted out to analyse the practical utility and actual impact of the test on the quality of care offered to the patient [8].

It is now worth taking a moment to critically analyse these newly emerged methods for their practical utility, with the purposes redefined. The diagnostic tests should not only provide details about the past disease activity but also be able to detect current disease status and predict the future susceptibility. The following section focuses on the microbiologic and biochemical investigations employed in periodontal diagnosis.

\section{Microbiological Investigations}

Recent developments in molecular biology techniques have enabled investigators to detect a much wider variety of bacterial species closely associated with periodontal disease [1216]. Detailed information on the individual microbiologic techniques is beyond the scope of the present paper; an overview of the available techniques is summarized in Table 1 [17-22]. There are some issues which are certainly associated with these techniques in general and might affect their clinical applicability and limit the practical usefulness of the microbiologic diagnostic techniques.

2.1. The Uncultivables. The techniques in molecular biology have obviated the necessity for bacterial culture of dental plaque samples [22, 23]. Most predominant bacterial species in the oral cavity have been identified using cultureindependent molecular methods based on sequence analysis of the 16S ribosomal RNA genes [24-37]. Collectively speaking, there are about 620 predominant oral bacterial species, of which about 35\% have not yet been cultured in vitro [21]. The need for study of these uncultivables to understand their exact position in the oral ecology and in the pathogenesis of periodontal disease keeps us far from deciphering the complete scenario.

2.2. "What Is Being Measured?" The microbiologic tests that measure periodontal pathogens do not necessarily measure periodontal disease. Bacterial pathogens can be present even in high numbers in periodontal pockets without loss of connective tissue attachment or alveolar bone. Therefore, assays for periodontal pathogens are not, of themselves, diagnostic for periodontal disease [22]. Mere presence of the suspected pathogens cannot be directly interpreted as disease, as most of the putative periodontal pathogens are found colonizing the healthy gingival sulci as well. All identified isolates of a particular bacterial species are not necessarily equally pathogenic or detrimental, for example, Aggregatibacter actinomycetemcomitans (A.a) and Porphyromonas gingivalis ( $P$. 
TABle 1: Various methods for identification of pathogens in periodontal infections.

\begin{tabular}{|c|c|}
\hline Method & Description \\
\hline $\begin{array}{l}\text { Culture methods } \\
\text { Selective } \\
\text { Nonselective }\end{array}$ & $\begin{array}{l}\text { Can detect up to 104-105 species selectively and } 103 \text { species nonselectively, } \\
\text { does not detect nonviable species, and takes approx. 1-3 weeks }\end{array}$ \\
\hline \multicolumn{2}{|l|}{ Immunological methods } \\
\hline Particle concentration fluorescence immunoassay & $\begin{array}{l}\text { Can detect up to } 104 \text { species, detects nonviable species, and takes approx. } \\
\text { minutes to hours }\end{array}$ \\
\hline DNA probe & $\begin{array}{l}\text { Detects up to } 102 \text { species, detects nonviable species, and takes approx. 1-48 } \\
\text { hours }\end{array}$ \\
\hline \multicolumn{2}{|r|}{ 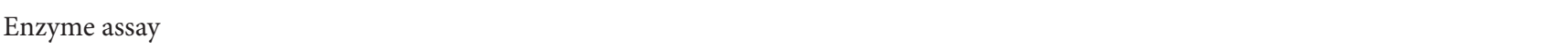 } \\
\hline Benzoyl-DL-arginine-2-naphthylamide (BANA) & $\begin{array}{l}\text { Detects } 104 \text { species, does not detect nonviable species, and takes approx. } 15 \\
\text { minutes }\end{array}$ \\
\hline \multicolumn{2}{|l|}{ Polymerase chain reaction } \\
\hline Single target PCR & Detects specific species directly from oral clinical samples \\
\hline Multiplex PCR & $\begin{array}{l}\text { Expansion of single target PCR, detects multiple species simultaneously and } \\
\text { detects up to } 10-100 \text { cells per PCR }\end{array}$ \\
\hline Real-time PCR & Detects and quantifies multiple species \\
\hline \multicolumn{2}{|l|}{ DNA-DNA hybridization } \\
\hline Fluorescence in situ hybridization (FISH) & $\begin{array}{l}\text { Quantify and determine special configuration and demonstrate the } \\
\text { morphology of individual bacterial cell in complex natural communities }\end{array}$ \\
\hline Checkerboard hybridization & $\begin{array}{l}\text { Hybridization of } 45 \text { DNA samples against } 30 \text { DNA probes on a single support } \\
\text { membrane }\end{array}$ \\
\hline Reverse-capture checkerboard hybridization & 16S ribosomal RNA based oligonucleotide checkerboard hybridization \\
\hline Oligonucleotide microarray technology & $\begin{array}{l}\text { A high sample-throughput, } 16 \mathrm{~S} \text { ribosomal RNA-based technology allows the } \\
\text { simultaneous detection of about } 300 \text { key and predominant bacterial species, } \\
\text { including species that have not yet been cultured }\end{array}$ \\
\hline \multicolumn{2}{|l|}{ Sequencing methods } \\
\hline 454 pyrosequencing & DNA is fragmented and amplified using special adaptors in an emulsion \\
\hline SOLiD & $\begin{array}{l}\text { PCR that binds to an agarose bead. Fragmented DNA is amplified on an } \\
\text { agarose bead }\end{array}$ \\
\hline Illumina/Solexa methodology & Utilises fragmented DNA and specialized adaptors attached to a slide \\
\hline
\end{tabular}

Adapted from [22].

gingivalis), and, lastly, a particular microorganism may not cause an identical disease in all infected hosts. So, the identified microorganisms represent only one aspect of this multifactorial disease [17].

2.3. Sampling. Information generated from microbiologic investigations is highly dependent on the sampling method employed. Assays for bacteria can only detect target species, that too when they are present in the patient sample. Since there may be over 100 different subgingival sample sites around a complete dentition, each harbouring a unique microbiologic profile, obtaining a representative sample poses another challenge. The findings suggest that different species of periodontal pathogens necessitate different sampling schemes [22]. The outcome of the analysis can further be affected by the method of sample collection $[12,19]$.

2.4. Information Provided. We now have microbiologic tools with the specificity and selectivity necessary to allow the investigator to determine the presence and the approximate proportion of a multitude of different subgingival species. An estimate of the proportion of a target species present is based on its contribution to the total number of bacterial species enumerated and not to total bacterial mass. So, such sort of variation can only give a clue about the proportion of the target species [12].

Even with the best of techniques available, we are yet unable to reliably state that we are aware of all bacterial species and taxa that are involved in the initiation and progression of periodontitis. Review of contemporary literature regarding the utility of microbial identification as an aid in the treatment planning of patients with periodontitis showed a limited number of studies, but the lack of appropriate controls, however, makes the interpretation of these results difficult and therefore the utility of microbial testing in developing specific treatment plans could not be ascertained. Similarly available evidence could not suggest a definitive benefit of microbiological testing as an indicator of healing or disease $[12,17,19]$. Although prospective studies monitoring patients after therapy would indicate that the use of microbial testing could aid in the selection of a more targeted therapy, mostly in patients with aggressive or recurrent periodontitis, 
again, the lack of clinical trials with adequate controls prevents from demonstrating the real value of microbial diagnosis. Therefore, the available evidence does not fully prove the utility of microbiological testing in periodontitis patients.

Periodontal diseases are infections caused by microorganisms that colonize the tooth surface at or below the gingival margin and accumulate as dental plaque. The biofilms (dental plaque) that colonize the tooth surface are extremely complex and remarkably resistant to host defense mechanisms and antimicrobial agents. Therefore, the mechanical plaque control (i.e., removal of supra- and subgingival plaque) remains the cornerstone in periodontal therapy such as self-performed oral hygiene, scaling and root planning, or periodontal surgery [38]. So microbial analysis cannot be regarded as a routine first visit investigation for all patients, but it can be reserved for specific clinical situations, such as to identify (by knowing specific microbial profiles) for targeted and effective antimicrobial therapy for managing susceptible patients. Another evidence emphasizing the significance of microbial analysis in therapeutic management is now emerging. Papapanou et al. suggested that the microbial content of the periodontal pocket is a determinant of gene expression in the gingival tissues and can potentially identify susceptible sites in terms of additional periodontal breakdown or unfavorable response to therapy [39]. These findings can serve as basis of subsequent studies for exploring the role of microbial testing. At present, only the rationale usage of microbial diagnostic techniques might benefit our patients, by saving on the time, pain, labour, and cost of repeat mechanical therapy, antibiotic usage, and surgical trauma, if we are able to formulate a better tailored treatment plan which is based on the diagnostic information obtained.

\section{Biochemical Analysis}

Biomarkers, whether produced by normal healthy individuals or by individuals affected by specific systemic diseases, are tell-tale molecules that could be used to monitor health status, disease onset, treatment response, and outcome [2]. Informative biomarkers can serve as early sentinels of disease. A huge body of literature was generated in the 1990s on the utility and value of individual biomarkers of periodontal disease activity, measured within gingival crevicular fluid under the following categories:

(i) markers of the presence or absence of periodontal pathogens,

(ii) markers of gingival and periodontal inflammation,

(iii) markers of the host's inflammatory-immune response to certain pathogenic species,

(iv) markers of host tissue destruction [10].

The principal biological media within which biomarkers were sought including saliva, serum, subgingival plaque, tissue biopsies, and gingival crevicular fluid, mouth-rinse [40, 41]. Gingival crevicular fluid became the analytical fluid of choice as it was the most specific to the periodontal tissues, could be collected noninvasively, and allowed site-specific analyses. However, molecular analysis of GCF elution was time consuming and laboratory based, technically demanding collection of sample leading to a small volume of the fluid $(1-5 \mu \mathrm{L})$. Despite these apparent diagnostic and technical disadvantages, GCF was still considered as a candidate potential oral fluid for the development of adjunctive noninvasive chair-side point-of-care diagnostic technology [4244] especially because tissue destructive MMPs and their bioactive regulators can conveniently be measured by distinct catalytic and noncatalytic immunoassays from GCF $[41,45]$. A plethora of biomarkers and diagnostic tests were developed thereafter, several of which demonstrated high levels of sensitivity, specificity, and diagnostic accuracy with respect to identifying and/or predicting disease activity at the site level $[10,46]$. In particular, Loos and Tjoa [47] undertook a critical review of biomarkers in gingival crevicular fluid and found that only eight of 94 in the literature of the time fulfilled any of the criteria for biomarker status. These eight biomarkers were alkaline phosphatase [48-54], $\beta$-glucuronidase $[52,55-$ 63], cathepsin B [64-69], MMP-8 and MMP-9 [52, 7082], dipeptidyl peptidases II and IV [65, 66, 68, 83], and neutrophil elastase $[46,52,61,63-66,76,84-86]$.

A number of diagnostic kits emerged based upon individual biomarkers within gingival crevicular fluid, but market research had not been performed that actively and the tests did not popularize much among practicing dentists due to several reasons: (1) time-consuming and laborious to perform; (2) difficult to interpret and understand; (3) site specific and the choice of site being problematic; (4) the results not materializing to alterations in therapeutic intervention; (5) expensive for routine use. As compared to GCF, collection of salivary and mouth-rinse samples was considered more convenient, practical, rapid, and noninvasive and requires neither professional stuff nor specific materials. Saliva and mouth-rinse represented a pooled sample from all periodontal sites providing an overall assessment of periodontal disease and health at subject level [41]. Whilst it was firmly established that gingival crevicular fluid was the most appropriate diagnostic medium to use in analyses, it became clear that whole-mouth analysis was far more practical, simpler, and cheaper, and thus saliva became the medium of choice in the 21st century [87]. Saliva had many advantages as a diagnostic fluid in that it was simple to collect using noninvasive techniques and provides a wholemouth summary analysis. Whole saliva could be affected by molecular constituents and cellular remnants from other oral niches, as well as systemic conditions $[88,89]$ which could have bearing on its diagnostic applications.

Principally it remains a surrogate fluid for gingival crevicular fluid and therefore assays need to be highly sensitive. In addition, saliva biochemistry varies with its origin (whole saliva or specific gland secretions), which are in turn affected by environmental and psychological stimuli. Therefore, it is not possible to fully quantify markers within saliva using chairside technologies, and qualitative analyses, or at best semiquantification, are all that can be reliably achieved [10].

MMP-8 or collagenase-2/neutrophil-collagenase was worked on extensively, being the major type of interstitial collagenase present in human periodontitis-affected gingival 
TABLE 2: Five-phase approach for translating research on biomarker applications.

\begin{tabular}{|c|c|c|}
\hline Process & Phases & Description \\
\hline Discovery: biomarkers and pathway elucidation & PHASE1 & $\begin{array}{l}\text { Exploratory study to identify potentially useful } \\
\text { biomarkers. }\end{array}$ \\
\hline Validation: efficacy in $2 \%$ population & PHASE2 & $\begin{array}{l}\text { To determine their capacity for distinguishing } \\
\text { between cases with disease and those without. }\end{array}$ \\
\hline \multirow[t]{2}{*}{ Cohort and longitudinal validation: efficacy in an at-risk population } & PHASE3 & $\begin{array}{l}\text { To determine the capacity of a biomarker to detect } \\
\text { preclinical disease. }\end{array}$ \\
\hline & PHASE4 & Prospective screening studies. \\
\hline Clinical use: diagnosis and prognosis & PHASE5 & $\begin{array}{l}\text { Large-scale population studies that evaluate } \\
\text { overall impact of screening on the population. }\end{array}$ \\
\hline
\end{tabular}

Adopted from [109].

tissue, gingival crevicular fluid, peri-implant sulcular fluid, saliva, and mouth-rinse samples [43]. Antibodies applied in the immunoassays for the detection of MMPs and their regulators affected the measurement outcomes [45, 90, 91]. Nevertheless, particularly MMP-8 immunoassays and activity assays targeting PMN-type MMP-8 isoenzyme species in oral fluids have been found to be useful to differentiate periodontitis/peri-implantitis and gingivitis sites/patients as well as healthy sites/subjects [44, 45, 90, 92]. These researchers utilized selective antibodies for detection of active MMP-8 in oral fluids for developing adjunctive diagnostic point-of-care/chair-side tests identifying sites susceptible for periodontitis progression and periodontitis affected patients [41]. Smoking has been found in several studies to decrease MMP-8 levels in GCF because of the effects on local blood circulation and lowered signs of inflammation [93, 94]. However, Mäntylä et al. [92] suggested that it cannot be regarded categorically that all smoking periodontitis patients have lower levels of MMP-8 in GCF and further in oral rinse sample as they detected the highest MMP-8 GCF levels in smoking subjects with poor response to conventional periodontal treatment (scaling and root planning, SRP). Simultaneous analysis of MMP-8 and TIMP-1 proved beneficial [90]. Also the effect of MMP-8 inhibiting SDD medication could be monitored by analyzing the salivary and oral rinse MMP-8 levels to find out when a possible break in medication would be possible or when the medication should be taken again $[95,96]$. The point-of-care MMP-8 immunotechnologies from oral fluids and serum/ plasma could be well adapted for monitoring of systemic inflammation $[41,89,97]$.

On the basis of our current understanding of the complexity of periodontitis, the identification of one single diagnostic marker for all forms of periodontal disease seems illusionary [47]. Several excellent reviews discuss these samples for targeted approaches to biomarker discovery $[86,87,98-$ 100]. As Bensalah et al. [101] have recently documented, six different types of biomarker can be differentiated as follows:

(i) early detection of disease,

(ii) diagnosis of presence or absence of disease,

(iii) prognosis of disease outcome and possible patient stratification for those at elevated risk of disease recurrence, (iv) prediction of treatment outcome,

(v) identification of patients who will respond well to a particular treatment,

(vi) surrogate end-points.

The proteomic era has made multiple biomarker analyses an achievable goal and advances in modern diagnostic technologies have made delivery at the point-of-care a realistic proposition. A multitude of biomarkers will improve sensitivity, specificity, and the diagnostic accuracy of tests, and early studies involving combinations of biomarkers in so-called lab-on-a-chip platforms have shown promising results $[2,47$, 102]. In addition, for a biomarker or a panel of biomarkers to be successfully employed within the clinical environment, they must also be objective, reproducible, easy to use, cheaper, and with greater sensitivity, specificity, and diagnostic accuracy than existing tests. Also in parallel to drug discovery is the process of validation through which biomarkers should pass through before appearing in clinical practice (Table 2) $[46,103]$. Validation of periodontal diagnostics will need to be benchmarked with existing gold standards of disease, including alveolar bone height and clinical attachment levels [40].

There is definitely an urgent need for a more sophisticated and precise predictor for periodontal disease. If a marker is capable of identifying the onset of disease activity or characterizing the transition between gingivitis and periodontitis (either by its simple presence or by being present at a certain concentration threshold), then we would potentially have a diagnostic tool that could become the standard of care in delivering periodontal treatment. This deficiency in knowledge about the initiation of disease activity at the subclinical level may not lie with the technical ability to identify biomarkers in saliva but may actually reside in what biomarkers to look for. In other words, we must focus to better understand the pathogenesis of periodontitis. It may well be that different sets of markers exist for initiating the disease process and associated with the presence of established inflammation. It may also be that markers that characterize the inflammatory process in individuals who develop periodontitis are different from those who present with chronic gingivitis (and never develop periodontitis) and lastly that markers of inflammation are not specific enough to predict the development of periodontitis [2]. 


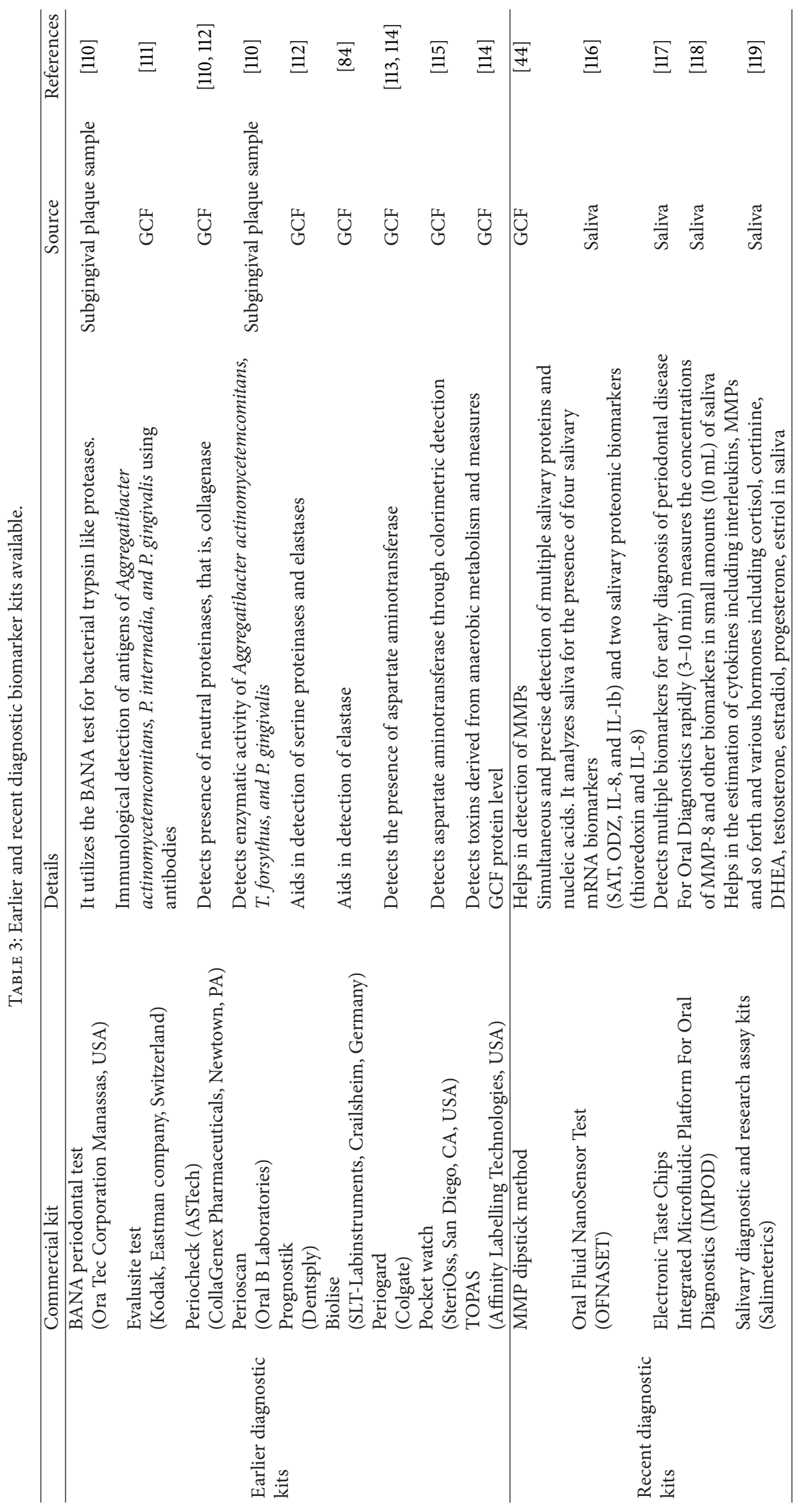


The key challenge is to elucidate a panel of biomarkers that differentiate health from periodontitis and, more importantly, gingivitis from periodontitis. This calls for performing studies in which gingivitis and periodontitis are induced experimentally in animal models. All markers that are potentially associated with initiating the disease process are monitored longitudinally (form health to the full-blown disease state) by salivary genomics, proteomics, and other state-of-the-art diagnostic techniques. A similar methodology could be adopted to analyse the treatment of disease, correlating periodontal healing and stability with the absence of such markers. The complexity of the associated microflora and the critical role of the host further heighten the issues for conducting the research regarding specific biomarkers for periodontal disease and might point towards exploring novel simulated animal models for studying these specific investigations. In human trials, for prospective investigations a combination of surrogate endpoints can be analysed for enhancing specificity while evaluating the biomarker.

It is highly unlikely that a single biomarker may prove to be a stand-alone measure for predicting periodontal disease activity. A combined analysis of proteomic, genomic, microbial, and other indicators is required to identify the set of biomarkers with the most favourable combination of sensitivity, specificity, reproducibility, and correlations with established disease diagnostic criteria. Emerging clinical applications of lab-on-a-chip (LOC) technologies as point-of-care (POC) diagnostics developed for systemic diseases are now being readily applied to periodontology. Many diagnostic kits have been commercialized and are being marketed (Table 3 ). The field of periodontology is now able to detect a panel of salivary biomarkers to predict disease, including matrix metalloproteinase-8 (MMP-8), microbial factors, and proinflammatory cytokines such as IL-1 beta [40]. These salivary biomarker detectors can be used in the office of a dentist or another healthcare provider for point-of-care disease screening and detection. The dental community is not generally familiar with mass screening of populations for oral and systemic diseases [40]. If more efficient periodontal therapy can be delivered, clinicians will be more likely to utilize new diagnostic approaches. Dentists will have greater involvement in the identification monitoring of oral and systemic disorders in the not too distant future.

Prospective healthcare is a new approach that incorporates all the power of current disease-oriented medicine but is based on the concept of strategic health planning, a proactive, prospective approach to care. In this system, individuals are evaluated to determine their baseline risk for a specific disease, their current health status, and their likelihood of developing specific clinical problems given their risks [102, $104,105]$. As mentioned before, allocation of resources to prevent periodontitis/peri-implantitis would be optimized and may help to reduce costs if diagnostic information would assist in identifying susceptible patients and help providing more specific prevention/treatment strategies for high-risk and low-risk patients. Saliva as a diagnostic and/or prognostic tool can improve and ease treatment planning in periodontics and implant dentistry, thus resulting in more predictable treatment outcomes and cost savings $[2,106]$. Periodontal oral POC devices will also enable masses to be screened; particularly underserved communities and resource limited areas as in developing nations may be accessed more efficiently. such applications might serve better for identification of at-risk groups and increase access to treatment for those most in need, improving public health in periodontology and the oral health field in general [40].

A careful analysis is mandatory, before adopting any newly emerged diagnostic test in the current clinical protocol. The novel test must be weighed against the conventional criteria of diagnosis in its sensitivity, specificity, validity, and reliability [107]. The benefit of having a particular piece of diagnostic information must not only outweigh the effort to obtain it on the level of each individual; however, the impact of a new diagnostic procedure should also be evaluated at a more global level, to maximize the overall benefit of the total investment in health care [8]. Adequate guidelines for the use of diagnostic routines should be issued and implemented from regulatory bodies in health care. Nevertheless, as new procedures are introduced in periodontology during these times of cost containment in health care, practitioners must use caution in deciding which particular patients would benefit from a comprehensive evaluation $[8,108]$.

\section{Conflict of Interests}

The authors declare that there is no conflict of interests regarding the publication of this paper.

\section{References}

[1] G. C. Armitage, "Periodontal diagnoses and classification of periodontal diseases," Periodontology 2000, vol. 34, pp. 9-21, 2004.

[2] W. V. Giannobile, T. Beikler, J. S. Kinney, C. A. Ramseier, T. Morelli, and D. T. Wong, "Saliva as a diagnostic tool for periodontal disease: current state and future directions," Periodontology 2000, vol. 50, no. 1, pp. 52-64, 2009.

[3] G. C. Armitage, “The complete periodontal examination," Periodontology 2000, vol. 34, pp. 22-33, 2004.

[4] D. L. Wolf and I. B. Lamster, "Contemporary concepts in the diagnosis of periodontal disease," Dental Clinics of North America, vol. 55, no. 1, pp. 47-61, 2011.

[5] I. B. Lamster and J. T. Grbic, "Diagnosis of periodontal disease based on analysis of the host response," Periodontology 2000, vol. 7, pp. 83-99, 1995.

[6] J. D. Beck, "Issues in assessment of diagnostic tests and risk for periodontal diseases," Periodontology 2000, vol. 7, pp. 100-108, 1995.

[7] Research Science and Therapy Committee of the American Academy of Periodontology, "Diagnosis of periodontal diseases," Journal of Periodontology, vol. 74, no. 8, pp. 1237-1247, 2003.

[8] A. Mombelli, "Critical issues in periodontal diagnosis," Periodontology 2000, vol. 39, pp. 9-12, 2005.

[9] J. M. Goodson, "Diagnosis of periodontitis by physical measurement: interpretation from episodic disease hypothesis," Journal of Periodontology, vol. 63, no. 4s, pp. 373-382, 1992. 
[10] I. L. Chapple, "Periodontal diagnosis and treatment-where does the future lie?" Periodontology 2000, vol. 51, no. 1, pp. 924, 2009.

[11] I. L. C. Chapple, J. B. Matthews, G. H. Thorpe, H. D. Glenwright, J. M. Smith, and M. S. Saxby, "A new ultrasensitive chemiluminescent assay for the site-specific quantification of alkaline phosphatase in gingival crevicular fluid," Journal of Periodontal Research, vol. 28, no. 4, pp. 266-273, 1993.

[12] L. M. Shaddox and C. Walker, "Microbial testing in periodontics: value, limitations and future directions," Periodontology 2000, vol. 50, no. 1, pp. 25-38, 2009.

[13] E. M. B. Tinoco, R. Stevens, D. Haubek, C.-H. Lai, S. Balachandran, and H. Preus, "Relationship of serotype, leukotoxin gene type and lysogeny in Actinobbacillus actinomycetemcomitans to periodontal disease status," European Journal of Oral Sciences, vol. 105, no. 4, pp. 310-317, 1997.

[14] P. S. Kumar, A. L. Griffen, M. L. Moeschberger, and E. J. Leys, "Identification of candidate periodontal pathogens and beneficial species by quantitative $16 \mathrm{~S}$ clonal analysis," Journal of Clinical Microbiology, vol. 43, no. 8, pp. 3944-3955, 2005.

[15] S. S. Socransky and A. D. Haffajee, "Periodontal microbial ecology," Periodontology 2000, vol. 38, no. 1, pp. 135-187, 2005.

[16] S. S. Socransky, A. D. Haffajee, C. Smith et al., "Use of checkerboard DNA-DNA hybridization to study complex microbial ecosystems," Oral Microbiology and Immunology, vol. 19, no. 6, pp. 352-362, 2004.

[17] P. C. Baehni and B. Guggenheim, "Potential of diagnostic microbiology for treatment and prognosis of dental caries and periodontal diseases," Critical Reviews in Oral Biology and Medicine, vol. 7, no. 3, pp. 259-277, 1996.

[18] J. Slots, "Microbial analysis in supportive periodontal treatment," Periodontology 2000, vol. 12, no. 1, pp. 56-59, 1996.

[19] P. M. Loomer, "Microbiological diagnostic testing in the treatment of periodontal diseases," Periodontology 2000, vol. 34, no. 1, pp. 49-56, 2004.

[20] A. J. van Winkelhoff and E. G. Winkel, "Microbiological diagnostics in periodontics: biological significance and clinical validity," Periodontology 2000, vol. 39, pp. 40-52, 2005.

[21] B. J. Paster and F. E. Dewhirst, "Molecular microbial diagnosis," Periodontology 2000, vol. 51, no. 1, pp. 38-44, 2009.

[22] J. J. Zambon and V. Haraszthy, "The laboratory diagnosis of periodontal infections," Periodontology 2000, vol. 7, pp. 69-82, 1995.

[23] U. B. Gobel, B. J. Paster, F. E. Dewhirst, and B. K. Choi, "Identification of uncultivahle spirochetes by PCR amplification of plaque DNA," Journal of Dental Research, vol. 72, p. 152, 1993.

[24] J. A. Aas, B. J. Paster, L. N. Stokes, I. Olsen, and F. E. Dewhirst, "Defining the normal bacterial flora of the oral cavity," Journal of Clinical Microbiology, vol. 43, no. 11, pp. 5721-5732, 2005.

[25] J. A. Aas, S. M. Barbuto, T. Alpagot, I. Olsen, F. E. Dewhirst, and B. J. Paster, "Subgingival plaque microbiota in HIV positive patients," Journal of Clinical Periodontology, vol. 34, no. 3, pp. 189-195, 2007.

[26] J. A. Aas, A. L. Griffen, S. R. Dardis et al., "Bacteria of dental caries in primary and permanent teeth in children and young adults," Journal of Clinical Microbiology, vol. 46, no. 4, pp. 14071417, 2008.

[27] M. R. Becker, B. J. Paster, E. J. Leys et al., "Molecular analysis of bacterial species associated with childhood caries," Journal of Clinical Microbiology, vol. 40, no. 3, pp. 1001-1009, 2002.
[28] F. E. Dewhirst, M. A. Tamer, R. E. Ericson et al., "The diversity of periodontal spirochetes by $16 \mathrm{~S}$ rRNA analysis," Oral Microbiology and Immunology, vol. 15, no. 3, pp. 196-202, 2000.

[29] D. Dymock, A. J. Weightman, C. Scully, and W. G. Wade, "Molecular analysis of microflora associated with dentoalveolar abscesses," Journal of Clinical Microbiology, vol. 34, no. 3, pp. 537-542, 1996.

[30] M. Faveri, M. P. A. Mayer, M. Feres, L. C. de Figueiredo, F. E. Dewhirst, and B. J. Paster, "Microbiological diversity of generalized aggressive periodontitis by $16 \mathrm{~S}$ rRNA clonal analysis," Oral Microbiology and Immunology, vol. 23, no. 2, pp. 112$118,2008$.

[31] C. E. Kazor, P. M. Mitchell, A. M. Lee et al., "Diversity of bacterial populations on the tongue dorsa of patients with halitosis and healthy patients," Journal of Clinical Microbiology, vol. 41, no. 2, pp. 558-563, 2003.

[32] I. Kroes, P. W. Lepp, and D. A. Relman, "Bacterial diversity within the human subgingival crevice," Proceedings of the National Academy of Sciences of the United States of America, vol. 96, no. 25, pp. 14547-14552, 1999.

[33] B. J. Paster, S. K. Boches, J. L. Galvin et al., "Bacterial diversity in human subgingival plaque," Journal of Bacteriology, vol. 183, no. 12, pp. 3770-3783, 2001.

[34] B. J. Paster, M. K. Russell, T. Alpagot et al., "Bacterial diversity in necrotizing ulcerative periodontitis in HIV-positive subjects," Annals of Periodontology, vol. 7, no. 1, pp. 8-16, 2002.

[35] D. Preza, I. Olsen, J. A. Aas, T. Willumsen, B. Grinde, and B. J. Paster, "Bacterial profiles of root caries in elderly patients," Journal of Clinical Microbiology, vol. 46, no. 6, pp. 2015-2021, 2008.

[36] M. Sakamoto, M. Umeda, and Y. Benno, "Molecular analysis of human oral microbiota," Journal of Periodontal Research, vol. 40, no. 3, pp. 277-285, 2005.

[37] J. F. Siqueira Jr. and I. N. Rôças, "The microbiota of acute apical abscesses," Journal of Dental Research, vol. 88, no. 1, pp. 61-65, 2009.

[38] S. S. Socransky and A. D. Haffajee, "Dental biofilms: difficult therapeutic targets," Periodontology 2000, vol. 28, no. 1, pp. 1255, 2002.

[39] P. N. Papapanou, J. H. Behle, M. Kebschull et al., "Subgingival bacterial colonization profiles correlate with gingival tissue gene expression," BMC Microbiology, vol. 9, article 221, 12 pages, 2009.

[40] W. V. Giannobile, J. T. McDevitt, R. S. Niedbala, and D. Malamud, "Translational and clinical applications of salivary diagnostics," Advances in Dental Research, vol. 23, no. 4, pp. 375-380, 2011.

[41] M. Hernandez, R. Vernal, T. Sorsa, T. Tervahartiala, P. Mäntylä, and J. Gamonal, "The role of immuno-inflammatory response in the pathogenesis of chronic periodontitis and development of chair-side point of care diagnostics," in Pathogenesis and Treatment of Periodontitis, N. Buduneli, Ed., chapter 3, InTech, Rijeka, Croatia, 2012, http://www.intechopen .com/books/pathogenesis-and-treatment-of-periodontitis/therole-of-immuno-inflammatory-response-in-the-pathogenesisof-chronic-periodontitis-and-developmen.

[42] T. Sorsa, P. Mäntylä, H. Rönkä et al., "Scientific basis of a matrix metalloproteinase- 8 specific chair-side test for monitoring periodontal and peri-implant health and disease," Annals of the New York Academy of Sciences, vol. 878, pp. 130-140, 1999.

[43] T. Sorsa, L. Tjäderhane, Y. T. Konttinen et al., "Matrix metalloproteinases: contribution to pathogenesis, diagnosis and treatment of periodontal inflammation," Annals of Medicine, vol. 38, no. 5, pp. 306-321, 2006. 
[44] P. Mäntylä, M. Stenman, D. F. Kinane et al., "Gingival crevicular fluid collagenase-2 (MMP-8) test stick for chair-side monitoring of periodontitis," Journal of Periodontal Research, vol. 38, no. 4, pp. 436-439, 2003.

[45] T. Sorsa, M. Hernández, J. Leppilahti, S. Munjal, L. Netuschil, and P. Mäntylä, "Detection of gingival crevicular fluid MMP8 levels with different laboratory and chair-side methods," Oral Diseases, vol. 16, no. 1, pp. 39-45, 2010.

[46] M. M. Grant, "What do 'omic technologies have to offer periodontal clinical practice in the future?” Journal of Periodontal Research, vol. 47, no. 1, pp. 2-14, 2012.

[47] B. G. Loos and S. Tjoa, "Host-derived diagnostic markers for periodontitis: do they exist in gingival crevice fluid?" Periodontology 2000, vol. 39, pp. 53-72, 2005.

[48] I. L. Chapple, H. D. Glenwright, J. B. Matthews, G. H. Thorpe, and P. J. Lumley, "Site-specific alkaline phosphatase levels in gingival crevicular fluid in health and gingivitis: cross-sectional studies," Journal of Clinical Periodontology, vol. 21, no. 6, pp. 409-414, 1994.

[49] H. J. Wright, I. L. Chapple, and J. B. Matthews, "Levels of TGF $\beta 1$ in gingival crevicular fluid during a 21-day experimental model of gingivitis," Oral Diseases, vol. 9, no. 2, pp. 88-94, 2003.

[50] I. L. C. Chappie, "Chemiluminescent assay of alkaline phosphatase in human gingival crevicular fluid: investigations with an experimental gingivitis model and studies on the source of the enzyme within crevicular fluid," Journal of Clinical Periodontology, vol. 23, no. 6, pp. 587-594, 1996.

[51] I. L. Chapple, I. Garner, M. S. Saxby, H. Moscrop, and J. B. Matthews, "Prediction and diagnosis of attachment loss by enhanced chemiluminescent assay of crevicular fluid alkaline phosphatase levels," Journal of Clinical Periodontology, vol. 26, no. 3, pp. 190-198, 1999.

[52] T. Hanioka, K. Takaya, Y. Matsumori, R. Matsuse, and S. Shizukuishi, "Relationship of the substance P to indicators of host response in human gingival crevicular fluid," Journal of Clinical Periodontology, vol. 27, no. 4, pp. 262-266, 2000.

[53] K. Nakashima, C. Giannopoulou, E. Andersen et al., "A longitudinal study of various crevicular fluid components as markers of periodontal disease activity," Journal of Clinical Periodontology, vol. 23, no. 9, pp. 832-838, 1996.

[54] K. Nakashima, N. Roehrich, and G. Cimasoni, "Osteocalcin, prostaglandin $\mathrm{E}_{2}$ and alkaline phosphatase in gingival crevicular fluid: their relations to periodontal status," Journal of Clinical Periodontology, vol. 21, no. 5, pp. 327-333, 1994.

[55] J. T. Grbic, I. B. Lamster, J. B. Fine et al., "Changes in gingival crevicular fluid levels of immunoglobulin a following therapy: association with attachment loss," Journal of Periodontology, vol. 70, no. 10, pp. 1221-1227, 1999.

[56] J. T. Grbic, R. E. Singer, H. H. Jans, R. S. Celenti, and I. B. Lamster, "Immunoglobulin isotypes in gingival crevicular fluid: possible protective role of IgA," Journal of Periodontology, vol. 66, no. 1, pp. 55-61, 1995.

[57] I. B. Lamster, "Evaluation of components of gingival crevicular fluid as diagnostic tests," Annals of Periodontology, vol. 2, no. 1, pp. 123-137, 1997.

[58] I. B. Lamster, R. Celenti, and J. L. Ebersole, “The relationship of serum IgG antidbody titers to periodontal pathogens to indicators of the host response in crevicular fluid," Journal of Clinical Periodontology, vol. 17, no. 7, pp. 419-425, 1990.

[59] I. B. Lamster, D. S. Harper, L. A. Fiorello, R. L. Oshrain, R. S. Celenti, and J. M. Gordon, "Lysosomal and cytoplasmic enzyme activity, crevicular fluid volume, and clinical parameters characterizing gingival sites with shallow to intermediate probing depths," Journal of Periodontology, vol. 58, no. 9, pp. 614-621, 1987.

[60] I. B. Lamster, L. G. Holmes, K. B. Gross et al., “The relationship of beta-glucuronidase activity in crevicular fluid to probing attachment loss in patients with adult periodontitis. Findings from a multicenter study," Journal of Clinical Periodontology, vol. 22, no. 1, pp. 36-44, 1995.

[61] I. B. Lamster, R. L. Oshrain, D. S. Harper, R. S. Celenti, C. A. Hovliaras, and J. M. Gordon, "Enzyme activity in crevicular fluid for detection and prediction of clinical attachment loss in patients with chronic adult periodontitis. Six month results," Journal of Periodontology, vol. 59, no. 8, pp. 516-523, 1988.

[62] I. B. Lamster, S. Wallenstein, S. Sengupta, and T. Duffy, "Withinmouth correlations for indicators of the host response in gingival crevicular fluid," Archives of Oral Biology, vol. 35, no. 10, pp. 779-783, 1990.

[63] L. F. Wolff, N. J. Koller, Q. T. Smith, A. Mathur, and D. Aeppli, "Subgingival temperature: relation to gingival crevicular fluid enzymes, cytokines, and subgingival plaque micro-organisms," Journal of Clinical Periodontology, vol. 24, no. 12, pp. 900-906, 1997.

[64] H. Y. Chen, S. W. Cox, and B. M. Eley, "Cathepsin B, $\alpha 2-$ macroglobulin and cystatin levels in gingival crevicular fluid from chronic periodontitis patients," Journal of Clinical Periodontology, vol. 25, no. 1, pp. 34-41, 1998.

[65] S. W. Cox and B. M. Eley, "Cathepsin B/L-, elastase-, tryptase-, trypsin- and dipeptidyl peptidase IV-like activities in gingival crevicular fluid. A comparison of levels before and after basic periodontal treatment of chronic periodontitis patients," Journal of Clinical Periodontology, vol. 19, no. 5, pp. 333-339, 1992.

[66] B. M. Eley and S. W. Cox, "The relationship between gingival crevicular fluid cathepsin B activity and periodontal attachment loss in chronic periodontitis patients: a 2-year longitudinal study," Journal of Periodontal Research, vol. 31, no. 6, pp. 381392, 1996.

[67] E. Ichimaru, M. Tanoue, M. Tani et al., "Cathepsin B in gingival crevicular fluid of adult periodontitis patients: identification by immunological and enzymological methods," Inflammation Research, vol. 45, no. 6, pp. 277-282, 1996.

[68] C. N. Kennett, S. W. Cox, and B. M. Eley, "Investigations into the cellular contribution to host tissue proteases and inhibitors in gingival crevicular fluid," Journal of Clinical Periodontology, vol. 24, no. 6, pp. 424-431, 1997.

[69] K. Kunimatsu, K. Yamamoto, E. Ichimaru, Y. Kato, and I. Kato, "Cathepsins B, H and L activities in gingival crevicular fluid from chronic adult periodontitis patients and experimental gingvitis subjects," Journal of Periodontal Research, vol. 25, no. 2, pp. 69-73, 1990.

[70] N. Buduneli, S. Vardar, G. Atilla, T. Sorsa, H. Luoto, and H. Baylas, "Gingival crevicular fluid matrix metalloproteinase-8 levels following adjunctive use of meloxicam and initial phase of periodontal therapy," Journal of Periodontology, vol. 73, no. 1, pp. 103-109, 2002.

[71] L. M. Golub, K. Siegel, N. S. Ramamurthy, and I. D. Mandel, "Some characteristics of collagenase activity in gingival crevicular fluid and its relationship to gingival diseases in humans," Journal of Dental Research, vol. 55, no. 6, pp. 1049-1057, 1976.

[72] M. Kiili, S. W. Cox, H. W. Chen et al., "Collagenase-2 (MMP-8) and collagenase-3 (MMP-13) in adult periodontitis: molecular 
forms and levels in gingival crevicular fluid and immunolocalisation in gingival tissue," Journal of Clinical Periodontology, vol. 29, no. 3, pp. 224-232, 2002.

[73] D. F. Kinane, I. B. Darby, S. Said et al., "Changes in gingival crevicular fluid matrix metalloproteinase-8 levels during periodontal treatment and maintenance," Journal of Periodontal Research, vol. 38, no. 4, pp. 400-404, 2003.

[74] W. Lee, S. Aitken, G. Kulkarni et al., "Collagenase activity in recurrent periodontitis: relationship to disease progression and doxycycline therapy," Journal of Periodontal Research, vol. 26, no. 6, pp. 479-485, 1991.

[75] W. Lee, S. Aitken, J. Sodek, and C. A. McCulloch, "Evidence of a direct relationship between neutrophil collagenase activity and periodontal tissue destruction in vivo: role of active enzyme in human periodontitis," Journal of Periodontal Research, vol. 30, no. 1, pp. 23-33, 1995.

[76] C.-M. Liu and L.-T. Hou, "Collagenase activity in the gingival crevicular fluid of periodontal patients," Journal of the Formosan Medical Association, vol. 92, no. 2, pp. 157-164, 1993.

[77] S. Mancini, R. Romanelli, C. A. Laschinger, C. M. Overall, J. Sodek, and C. A. G. McCulloch, "Assessment of a novel screening test for neutrophil collagenase activity in the diagnosis of periodontal diseases," Journal of Periodontology, vol. 70, no. 11, pp. 1292-1302, 1999.

[78] T. Nakamura, J.-I. Kido, R. Kido et al., "The association of calprotectin level in gingival crevicular fluid with gingival index and the activities of collagenase and aspartate aminotransferase in adult periodontitis patients," Journal of Periodontology, vol. 71, no. 3, pp. 361-367, 2000.

[79] T. Nomura, A. Ishii, Y. Oishi, H. Kohma, and K. Hara, “Tissue inhibitors of metalloproteinases level and collagenase activity in gingival crevicular fluid: the relevance to periodontal diseases," Oral Diseases, vol. 4, no. 4, pp. 231-240, 1998.

[80] L. Persson, J. Bergström, and A. Gustafsson, "Effect of tobacco smoking on neutrophil activity following periodontal surgery," Journal of Periodontology, vol. 74, no. 10, pp. 1475-1482, 2003.

[81] R. Romanelli, S. Mancini, C. Laschinger, C. M. Overall, J. Sodek, and C. A. McCulloch, "Activation of neutrophil collagenase in periodontitis," Infection and Immunity, vol. 67, no. 5, pp. 23192326, 1999.

[82] Y. T. Teng, J. Sodek, and C. A. McCulloch, "Gingival crevicular fluid gelatinase and its relationship to periodontal disease in human subjects," Journal of Periodontal Research, vol. 27, no. 5, pp. 544-552, 1992.

[83] M. I. Gazi, S. W. Cox, D. T. Clark, and B. M. Eley, "Comparison of host tissue and bacterial dipeptidyl peptidases in human gingival crevicular fluid by analytical isoelectric focusing," Archives of Oral Biology, vol. 40, no. 8, pp. 731-736, 1995.

[84] G. C. Armitage, M. K. Jeffcoat, D. E. Chadwick et al., "Longitudinal evaluation of elastase as a marker for the progression of periodontitis," Journal of Periodontology, vol. 65, no. 2, pp. 120$128,1994$.

[85] Q. T. Smith, L. Harriman, G. S. Au et al., "Neutrophil elastase in crevicular fluid: comparison of a middle-aged general population with healthy and periodontitis groups," Journal of Clinical Periodontology, vol. 22, no. 12, pp. 935-941, 1995.

[86] I. B. Lamster, E. Kaufman, J. T. Grbic, L. J. Winston, and R. E. Singer, " $\beta$-glucuronidase activity in saliva: relationship to clinical periodontal parameters," Journal of Periodontology, vol. 74, no. 3, pp. 353-359, 2003.
[87] L. Zhang, B. S. Henson, P. M. Camargo, and D. T. Wong, "The clinical value of salivary biomarkers for periodontal disease," Periodontology 2000, vol. 51, no. 1, pp. 25-37, 2009.

[88] E. Buduneli, P. Mäntylä, G. Emingil et al., "Acute myocardial infarction is reflected in salivary matrix metalloproteinase-8 activation level," Journal of Periodontology, vol. 82, no. 5, pp. 716-725, 2011.

[89] N. Buduneli and D. F. Kinane, "Host-derived diagnostic markers related to soft tissue destruction and bone degradation in periodontitis," Journal of Clinical Periodontology, vol. 38, no. 11, pp. 85-105, 2011.

[90] J. M. Leppilahti, M.-M. Ahonen, M. Hernández et al., "Oral rinse MMP-8 point-of-care immuno test identifies patients with strong periodontal inflammatory burden," Oral Diseases, vol. 17, no. 1, pp. 115-122, 2011.

[91] M. Gürsoy, E. Könönen, U. K. Gürsoy, T. Tervahartiala, R. Pajukanta, and T. Sorsa, "Periodontal status and neutrophilic enzyme levels in gingival crevicular fluid during pregnancy and postpartum," Journal of Periodontology, vol. 81, no. 12, pp. 1790 1796, 2010.

[92] P. Mäntylä, M. Stenman, D. Kinane et al., "Monitoring periodontal disease status in smokers and nonsmokers using a gingival crevicular fluid matrix metalloproteinase-8-specific chair-side test," Journal of Periodontal Research, vol. 41, no. 6, pp. 503-512, 2006.

[93] B. Söder, "Neutrophil elastase activity, levels of prostaglandin E2, and matrix metalloproteinase- 8 in refractory periodontitis sites in smokers and non-smokers," Acta Odontologica Scandinavica, vol. 57, no. 2, pp. 77-82, 1999.

[94] B. Söder, L. J. Jin, and S. Wickholm, "Granulocyte elastase, matrix metalloproteinase- 8 and prostaglandin $\mathrm{E}_{2}$ in gingival crevicular fluid in matched clinical sites in smokers and nonsmokers with persistent periodontitis," Journal of Clinical Periodontology, vol. 29, no. 5, pp. 384-391, 2002.

[95] L. M. Golub, M. L. Hsi, J. A. Stoner et al., "Subantimicrobialdose doxycycline modulates gingival crevicular fluid biomarkers of periodontitis in postmenopausal osteopenic women," Journal of Periodontology, vol. 79, no. 8, pp. 1409-1418, 2008.

[96] R. A. Reinhardt, J. A. Stoner, L. M. Golub et al., "Association of gingival crevicular fluid biomarkers during periodontal maintenance with subsequent progressive periodontitis," Journal of Periodontology, vol. 81, no. 2, pp. 251-259, 2010.

[97] A. M. Tuomainen, K. Nyyssönen, J. A. Laukkanen et al., "Serum matrix metalloproteinase- 8 concentrations are associated with cardiovascular outcome in men," Arteriosclerosis, Thrombosis, and Vascular Biology, vol. 27, no. 12, pp. 2722-2728, 2007.

[98] F. G. Oppenheim, E. Salih, W. L. Siqueira, W. Zhang, and E. J. Helmerhorst, "Salivary proteome and its genetic polymorphisms," Annals of the New York Academy of Sciences, vol. 1098, pp. 22-50, 2007.

[99] N. Ozmeric, "Advances in periodontal disease markers," Clinica Chimica Acta, vol. 343, no. 1-2, pp. 1-16, 2004.

[100] M. Taba Jr., J. Kinney, A. S. Kim, and W. V. Giannobile, "Diagnostic biomarkers for oral and periodontal diseases," Dental Clinics of North America, vol. 49, no. 3, pp. 551-571, 2005.

[101] K. Bensalah, F. Montorsi, and S. F. Shariat, "Challenges of cancer biomarker profiling," European Urology, vol. 52, no. 6, pp. 16011609, 2007.

[102] R. Snyderman and J. Langheier, "Prospective health care: the second transformation of medicine," Genome Biology, vol. 7, no. 2, article 104, 2006. 
[103] B. M. Eley and J. D. Manson, Periodontics, Wright, Edinburgh, UK, 5th edition, 2004.

[104] R. Snyderman and R. S. Williams, "Prospective medicine: the next health care transformation," Academic Medicine, vol. 78, no. 11, pp. 1079-1084, 2003.

[105] R. Snyderman and Z. Yoedlono, "Pospective care: a personalized, preventative approach to medicine," Pharmacogenomics, vol. 7, no. 1, pp. 5-9, 2006.

[106] C. A. Ramseier, T. Morelli, J. S. Kineey et al., "Periodontal disease: salivary diagnostics," in Salivary Diagnostics, pp. 156168, Wiley Blackwell, Ames, Iowa, USA, 2008.

[107] S. J. Lord, L. Irwig, and R. J. Simes, "When is measuring sensitivity and specificity sufficient to evaluate a diagnostic test, and when do we need randomized trials?" Annals of Internal Medicine, vol. 144, no. 11, pp. 850-855, 2006.

[108] I. B. Lamster, "In-office diagnostic tests and their role in supportive periodontal treatment," Periodontology 2000, vol. 12, no. 1, pp. 49-55, 1996.

[109] B. J. Baum, J. R. Yates III, S. Srivastava, D. T. W. Wong, and J. E. Melvin, "Scientific frontiers: emerging technologies for salivary diagnostics," Advances in Dental Research, vol. 23, no. 4, pp. 360-368, 2011.

[110] K. W. Hemmings, G. S. Griffiths, and J. S. Bulman, "Detection of neutral protease (Periocheck) and BANA hydrolase (Perioscan) compared with traditional clinical methods of diagnosis and monitoring of chronic inflammatory periodontal disease," Journal of Clinical Periodontology, vol. 24, no. 2, pp. 110-114, 1997.

[111] B. P. Boyer, C. C. Ryerson, H. S. Reynolds, J. J. Zambon, R. J. Genco, and B. Snyder, "Colonization by Actinobacillus actinomycetemcomitans, Porphyromonas gingivalis and Prevotella intermedia in adult periodontitis patients as detected by the antibody-based Evalusite Test," Journal of Clinical Periodontology, vol. 23, no. 5, pp. 477-484, 1996.

[112] R. C. Page, "Host response tests for diagnosing periodontal diseases," Journal of Periodontology, vol. 63, no. 4, pp. 356-366, 1992.

[113] G. R. Persson, M. Alves, D. Chambers et al., "A multicenter clinical trial of PerioGard in distinguishing between diseased and healthy periodontal sites. (I). Study design, methodology and therapeutic outcome," Journal of Clinical Periodontology, vol. 22, no. 10, pp. 794-803, 1995.

[114] K. Shimada, T. Mizuno, K. Ohshio, M. Kamaga, S. Murai, and K. Ito, "Analysis of aspartate aminotransferase in gingival crevicular fluid assessed by using PocketWatch: a longitudinal study with initial therapy," Journal of Clinical Periodontology, vol. 27, no. 11, pp. 819-823, 2000.

[115] B. M. Eley and S. W. Cox, "Advances in periodontal diagnosis. 8. Commercial diagnostic kits based on GCF proteolytic and hydrolytic enzyme levels," British Dental Journal, vol. 184, no. 8, pp. 373-376, 1998.

[116] UCLA Collaborative Oral Fluids Diagnostic Research Center, 2006, http://hspp.ucla.edu/.

[117] N. Christodoulides, S. Mohanty, C. S. Miller et al., "Application of microchip assay system for the measurement of C-reactive protein in human saliva," Lab on a Chip, vol. 5, no. 3, pp. 261269, 2005.

[118] A. E. Herr, A. V. Hatch, D. J. Throckmorton et al., "Microfluidic immunoassays as rapid saliva-based clinical diagnostics," Proceedings of the National Academy of Sciences of the United States of America, vol. 104, no. 13, pp. 5268-5273, 2007.

[119] "Salivary research and diagnostic kits," https://www.salimetrics .com/assay-kits. 


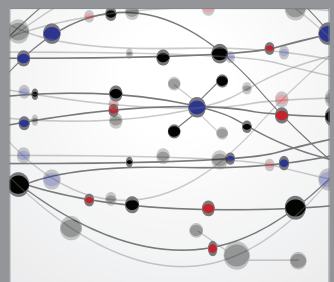

The Scientific World Journal
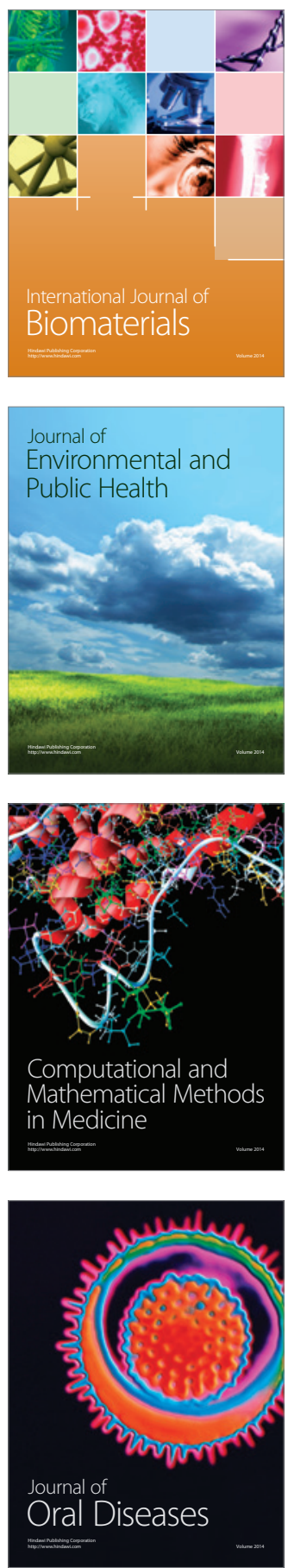
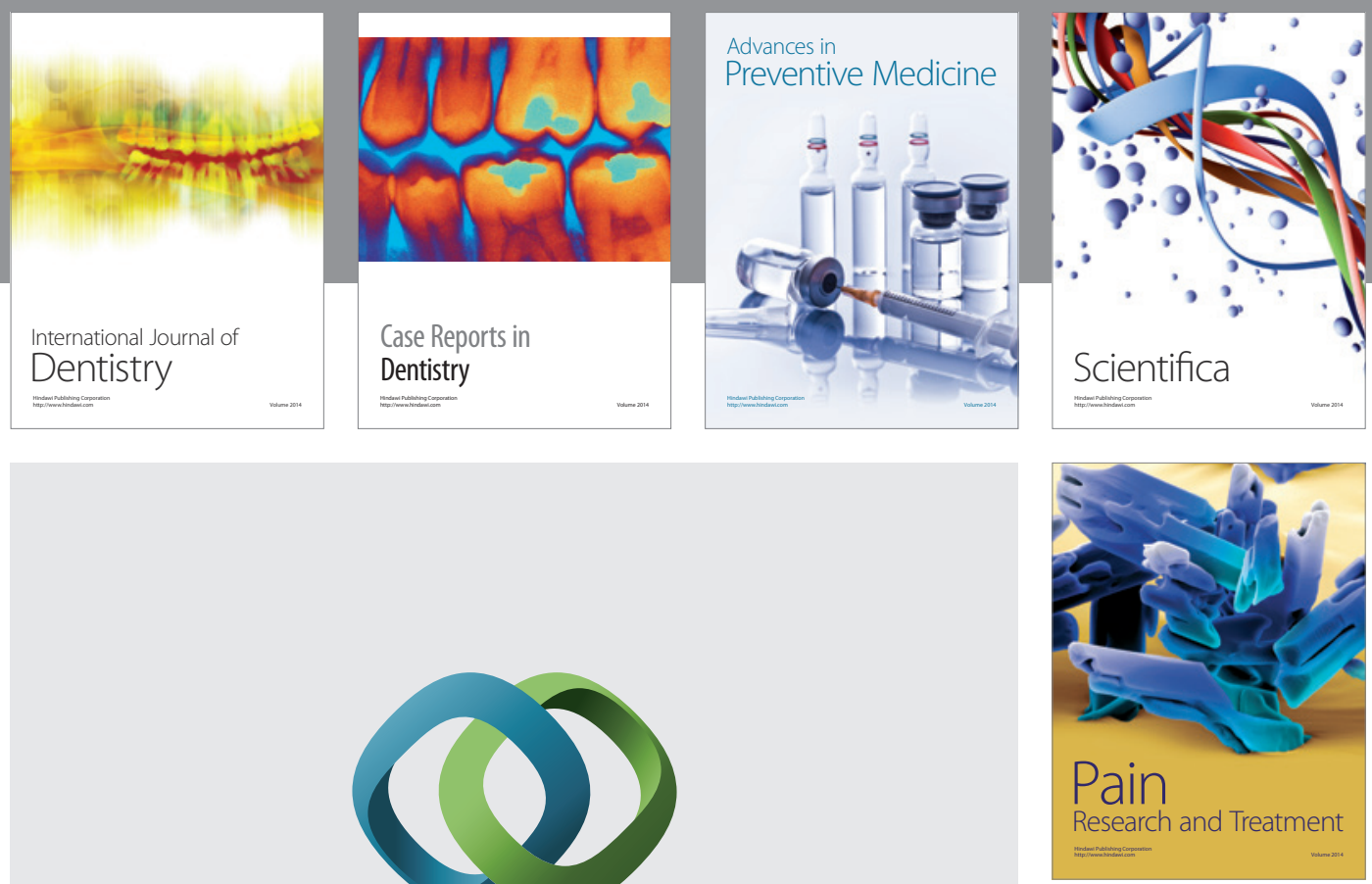

\section{Hindawi}

Submit your manuscripts at

http://www.hindawi.com
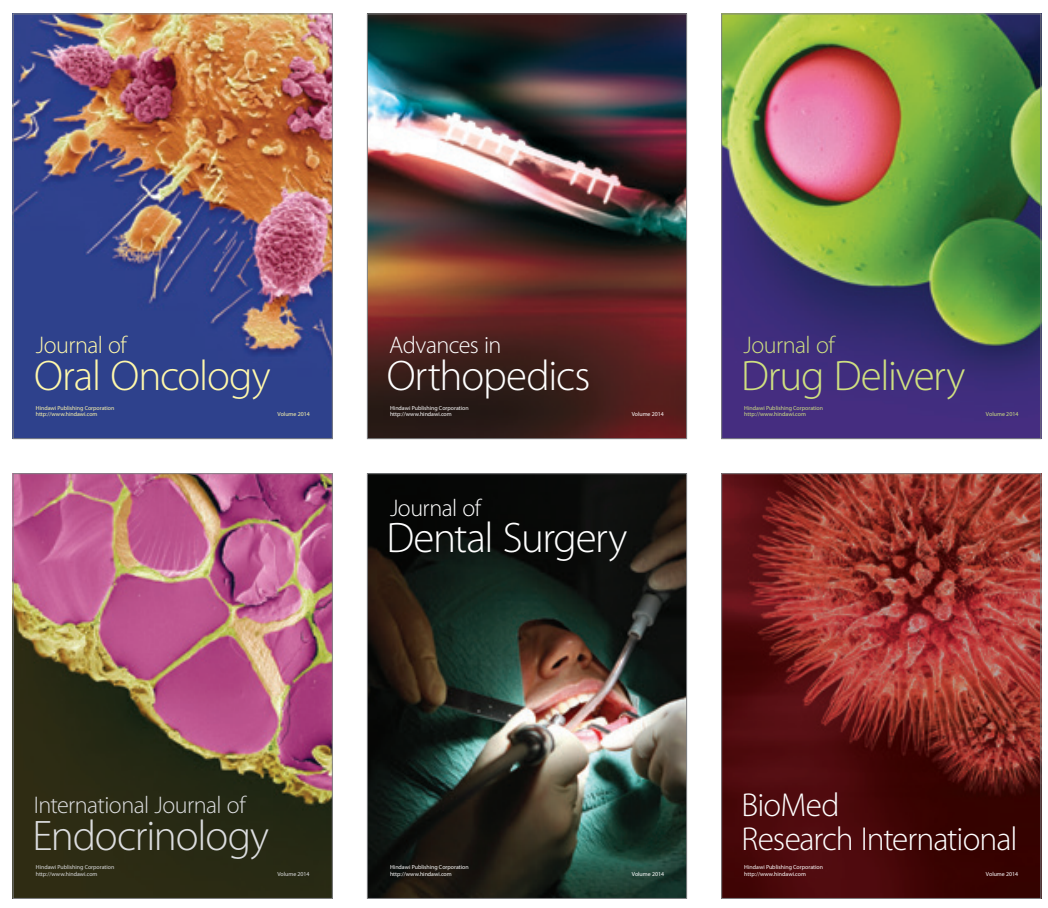

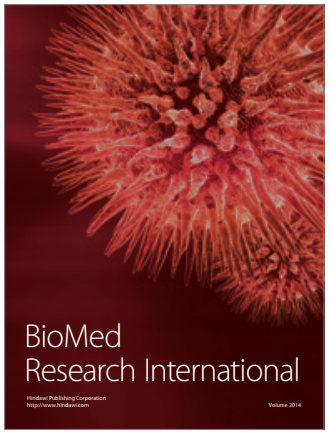

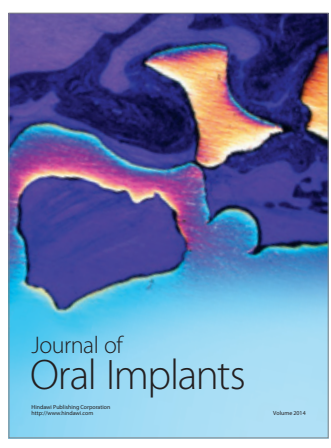
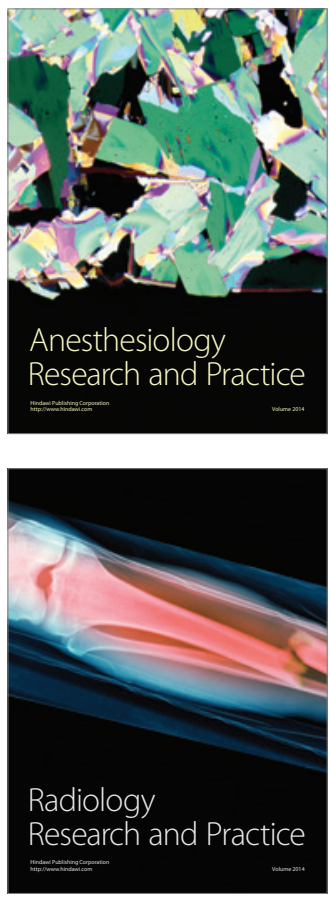